\title{
Role of Interleukin-6 in Lung Complications in Patients With COVID-19: Therapeutic Implications
}

\author{
KAREL SMETANA, JR. ${ }^{1,2}$ and JAN BRÁBEK ${ }^{2,3}$ \\ ${ }^{1}$ Institute of Anatomy, First Faculty of Medicine, Charles University, Prague, Czech Republic; \\ ${ }^{2}$ BIOCEV, Vestec, Czech Republic; \\ ${ }^{3}$ Department of Cell Biology, Faculty of Sciences, Charles University, Prague, Czech Republic
}

\begin{abstract}
COVID-19 is viral respiratory infection with frequently fatal lung complications in the elderly or in people with serious comorbidities. Lung destruction appears to be associated with a cytokine storm related to an increased level of interleukin-6 (IL6). Therapeutic targeting of the interleukin-6 signaling pathway can attenuate such a cytokine storm and can be beneficial for patients with COVID-19 in danger of pulmonary failure. This article demonstrates the importance of IL6 in progression of disease and the possibility of inhibition of IL6 signaling in COVID-19 therapy.
\end{abstract}

COVID-19 is pandemic respiratory infection caused by coronavirus severe acute respiratory syndrome-coronavirus 2 (SARS-CoV-2), which originated in mainland China. The majority of infected persons are asymptomatic or only have a mild course of disease. Unfortunately, the elderly are at particular risk of serious complications associated with damage to the lung resulting in the risk of fatal respiratory failure (1-3). This article demonstrates importance of interleukin-6 (IL6) in progression of this disease and the possibility of inhibiting IL6 signaling in COVID-19 therapy.

This article is freely accessible online.

Correspondence to: Jan Brábek, BIOCEV, Průmyslová 595, 25250 Vestec, Czech Republic. Tel: +42 0325873900, e-mail: jan.brabek@natur.cuni.cz; Karel Smetana Jr., Institute of Anatomy, $1^{\text {st }}$ Faculty of Medicine, Charles University, U Nemocnice 3, 128 00 Prague 2, Czech Republic. Tel: +42 0224965873, e-mail: karel.smetana@lf1.cuni.cz

Key Words: SARS-CoV-2, lung failure, cytokine storm, IL6, COVID-19 therapy, review.

\section{Cytokine Storm}

Serious lung injury is associated with a cytokine storm as was demonstrated in similar diseases SARS and Middle East respiratory syndrome (MERS) (4-6) exhibiting signs of lung fibrosis as was also detected in patients with COVID-19 (7). It can be, therefore, hypothesized that lung injury in COVID19 may be also associated with this pathology (8). Pedersen and Ho observed increased cytokine levels [IL6, IL10 and tumor necrosis factor $\alpha(\mathrm{TNF} \alpha)$ ], lymphopenia (of $\mathrm{CD}^{+}$and $\mathrm{CD}^{+}$T-cells), reduced interferon $\gamma($ IFN $\gamma)$ expression in $\mathrm{CD} 4^{+} \mathrm{T}$-cells, and immunosuppression in patients with severe COVID-19 (8), which fulfil the criteria for the existence of a cytokine storm.

\section{Interleukin-6}

IL6 is critically important for the initiation and progression of a cytokine storm. Primarily, this cytokine stimulates inflammation but it also has other important functions such the stimulation of cell proliferation and migration in wound healing and in cancer, where it increases metastasis. IL6 is recognized by two types of receptors which is important from the functional point of view. However, IL6 also has important metabolic effects, controlling the metabolism of adipocytes, striated musculature and hepatocytes. It can stimulate catabolic pathways to promote senility/cancer wasting and cachexia. Moreover, IL6 crosses the brain-blood barrier and is recognized by neurons that can underlie some psychotic problems and anorexia (10-12). In this aspect, IL6 plays an important role in other pathological situations such as sepsis and syndrome including thrombocytopenia, anasarca, myelofibrosis, renal dysfunction, organomegaly (TAFRO) syndrome $(13,14)$. The role of IL6-signal transducer and activator of transcription 3 (STAT3) in tissue fibrosis, including lung damage, is well established (15). 
A

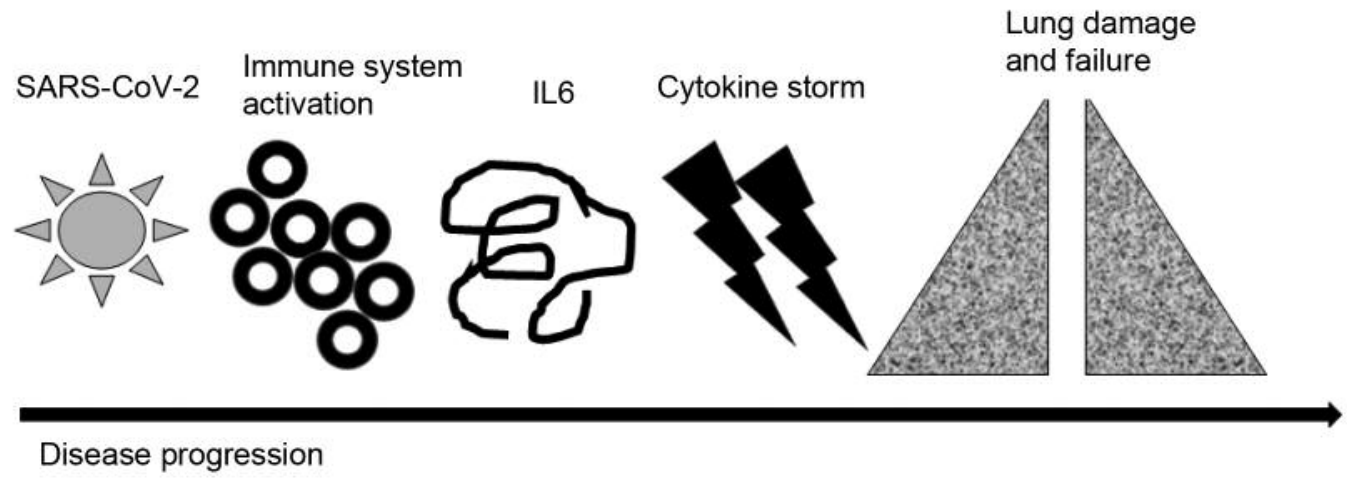

B

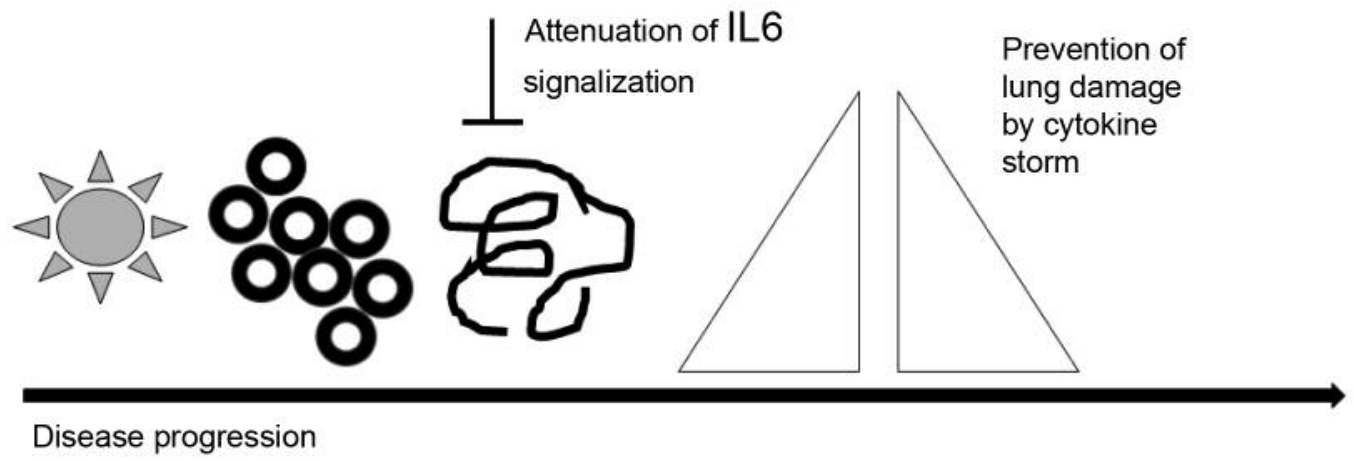

Figure 1. The role of interleukin-6 (IL6) in a cytokine storm. A: Infection by severe acute respiratory syndrome-coronavirus 2 (SARS-CoV-2) activates the immune system, which can produce an extremely higher amount of IL6 than is necessary. The abundant production of IL6 is important for the initiation of a cytokine storm that is subsequently responsible for lung damage and failure. B: Attenuation of IL6 signaling by suppression of its production (antimalarial drugs) or by targeting of its receptor complex (tozilizumab, bazedoxifene) has an inhibitory effect on the cytokine storm and protects the lungs from damage.

\section{Blocking of IL6 in COVID-19}

Therapeutic blocking of IL6 signaling has been successfully used in the therapy of autoimmune diseases. It was also tested in anticancer therapy, but its efficiency was not high when monotherapy alone was employed $(16,17)$. However, efficiency was improved by simultaneous targeting of other cytokines (18). In the context of this article, blockade of the IL6 signaling cascade can attenuate the cytokine storm (19) in selected patients exhibiting symptoms of cytokine storm, for example monitored by the level of factors such as ferritin (8).

The monoclonal antibody tocilizumab targeted against IL6 receptor has been successfully used for the therapy of rheumatoid arthritis. Preliminary results demonstrated a good effect of this antibody on the treatment of patients with COVID-19 with lung complications $(20,21)$ resulted in the US Food and Drug Administration approval of phase III clinical study (22). However, a clinical trial is necessary before it can be introduced into the anti-COVID-19 clinical arsenal. Humanized antibodies to IL6 receptor from other companies (sarilumab, siltuximab) are also about to enter phase I-III clinical trials for the prevention and management of lung damage in patients confirmed to have COVID-19.

Antimalarials such as chloroquine/hydroxychloroquine are used for therapy of parasitic diseases, as well as for therapy of some autoimmune pathologies, such as inflammatory bowel disease and lupus. Their effect is anti-inflammatory where they negatively influence the production of IL6 (23, 24). From this point of view, these substances are also good candidates for treatment of COVID-19-related lung complications (25). Employment of these substances is not without complications but for this indication, the benefit for patients will prevail (26).

Another therapeutic affecting the interaction of IL6 with its receptor, and the glycoprotein 130 (GP130) axis is bazedoxifene. This was designed as an estrogen analog for treatment of postmenopausal osteoporosis. However, this drug also interacts with GP130, part of the IL6 receptor (27, 28 ), where it prevents the binding of IL6 to the receptor. Bazedoxifene exhibits anti-inflammatory activity in arthritis (29) and due to its anti-IL6 activity was also found to have anticancer effects in various experimental setups (30-34). It has been observed that mortality from COVID-19 is gender- 
dependent, whereby men are more sensitive than women (35, 36). This finding has not yet been explained but in this context, the estrogenic activity of bazedoxifene might, hypothetically, also be promising.

It can be hypothesised that bazedoxifene may represent a cheaper and easier alternative to humanized IL6 receptor antibodies for treatment of COVID-19-related lung complications. Moreover, the function of bazedoxifene as an estrogen analog might also be effective against SARS-CoV2 entry and replication. Consistently, the in vitro preliminary results indicate bazedoxifene activity against COVID-19 (34). The principles of anti-IL6 therapy in COVID-19 are summarized in Figure 1.

\section{Conclusion}

Inhibitors of IL6 signaling represent a promising approach that can be employed for attenuation of a cytokine storm and might be beneficial for patients with COVID-19.

\section{Conflicts of Interest}

The Authors declare no conflicts of interest.

\section{Authors' Contributions}

K.S. and J.B. collected data and prepared the article.

\section{Acknowledgements}

This research was funded by the Operational Programme Research, Development and Education under the project "Center for Tumor Ecology - Research of the Cancer Microenvironment Supporting Cancer Growth and Spread" (reg. No. CZ.02.1.01/0.0/0.0/ 16_019/0000785),by the Research and Development for Innovations Operational Program under project no. CZ.1.05/2.1.00/19.0400 (cofinanced by the European Regional Development Fund and the state budget of the Czech Republic) and the Charles University programme Q28.

\section{References}

1 Chen N, Zhou M, Dong X, Qu J, Gong F, Han Y, Qiu Y, Wang J, Liu Y, Wei Y, Xia J, Yu T, Zhang X and Zhang L: Epidemiological and clinical characteristics of 99 cases of 2019 novel coronavirus pneumonia in Wuhan, China: A descriptive study. Lancet 395: 507-513, 2020. PMID: 32007143. DOI: 10.1016/S0140-6736(20)30211-7

2 Guo Y-R, Cao Q-D, Hong Z-S, Tan Y-Y, Chen S-D, Jin H-J. Tan $\mathrm{K}-\mathrm{S}$, Wang D-Y and Yan Y: The origin, transmission and clinical therapies on coronavirus disease 2019 (COVID-19) outbreak an update on the status. Mil Med Res 7: 11, 2020. PMID: 32169119. DOI: $10.1186 / \mathrm{s} 40779-020-00240-0$

3 Liu Y, Yang Y, Zhang C, Huang F, Wang F, Yuan J, Wang Z, Li Jin, Li Jia, Feng C, Zhang Z, Wang L, Peng L, Chen L, Qin Y, Zhao D, Tan S, Yin L, Xu J, Zhou C, Jiang C and Liu L: Clinical and biochemical indexes from 2019-nCoV-infected patients linked to viral loads and lung injury. Sci China Life Sci 63: 364374, 2020. PMID: 32048163. DOI:10.1007/s11427-020-1643-8

4 Channappanavar $\mathrm{R}$ and Perlman S: Pathogenic human coronavirus infections: causes and consequnces of cytokine storm and immunopathology. Semin Immunopathol 39: 529-539, 2017. PMID: 28466096. DOI: 10.1007/s00281-017-0629-x

5 Lau SKP, Lau CCY, Chan K-H, Li CPY, Chen H, Jin D-Y, Chan JFW, Woo PCY and Yuen K-Y: Delayed induction of proinflammatory cytokines and suppression of innate antiviral response by the novel Middle East respiratory syndrome coronavirus: Implications for pathogenesis and treatment. J Gen Virol 94: 2679-2690, 2013. PMID: 24077366. DOI: 10.1099/ vir. $0.055533-0$

6 Mahmud-Al-Rafa A, Majumder A, Rahman KMT, Hasan AMM, Islam KMD, Taylor-Robinson AW and Billah M: Decoding the enigma of antiviral crisis: Does one target molecule regulate all? Cytokine 115: 13-23, 2019. PMID: 30616034. DOI: 10.1016/ j.cyto.2018.12.008

7 Wang J, Wang BJ, Yang JC, Wang MY, Chen C, Luo GX and He WF: Advances in the research of mechanism of pulmonary fibrosis induced by corona Virus disease 2019 and the corresponding therapeutic measures. Zhonghua Shao Shang Za Zhi 36: E006, 2020. PMID: 32174095. DOI: 10.3760/ cma.j.cn501120-20200307-00132

8 Mehta P, McAuley DF, Brown M, Sanchez E, Tattersall RS and Manson JJ: COVID-19: consider cytokine storm syndromes and immunosuppression. Lancet 395: 1033-1034, 2020. PMID: 32192578. DOI: 10.1016/S0140-6736(20)30628-0

9 Pedersen SF and Ho YC: SARS-CoV-2: A storm is raging. J Clin Invest 2020: 137647, 2020. PMID: 32217834. PMID: 30766805. DOI: $10.1016 / \mathrm{S} 0140-6736(20) 30628-0$

10 White JP: IL-6, cancer and cachexia: metabolic dysfunction creates the perfect storm. Transl Cancer Res 6(Suppl 2): S280S285, 2017. PMID: 30766805. DOI: 10.21037/tcr.2017.03.52

11 Lacina L, Kodet O, Dvořánková B, Szabo P and Smetana K Jr.: Ecology of melanoma cell. Histol Histopathol 33: 247-254, 2018. DOI: $10.14670 / \mathrm{HH}-11-926$

12 Lacina L, Brábek J, Král V, Kodet $\mathrm{O}$ and Smetana K Jr.: Interleukin-6: A molecule with complex biological impact in cancer. Histol Histopathol 34: 125-136, 2019. PMID: 28849859. DOI: 10.14670/HH-18-033

13 Krüttgen A and Rose-John S: Interleukin-6 in sepsis and capillary leakage syndrome. J Interferon Cytokine Res 32: 6065, 2012. PMID: 22136372. DOI: 10.1089/jir.2011.0062

14 Simons M, Apor E, Butera JN and Treaba DO: TAFRO Syndrome associated with EBV and successful triple therapy treatment: Case report and review of the literature. Case Rep Hematol 2016: 4703608, 2016. DOI: 10.1155/2016/4703608

15 Knight D, Mutsaers SE and Prêle CM: STAT3 in tissue fibrosis: Is there a role in the lung? Pulm Pharmacol Ther 24: 193-198, 2011. PMID: 27777802. DOI: 10.1016/j.pupt.2010.10.005

16 Johnson DE, O'Keefe RA and Grandis JR: Targeting the IL6/JAK/STAT3 signalling axis in cancer. Nat Rev Clin Oncol 15: 234-248, 2018. PMID: 29405201. DOI: 10.1038/nrclinonc.2018.8

17 Pappas DA, Etzel CJ, Crabtree M, Blachley T, Best J, Zlotnick S, Kremer JM: Effectiveness of Tocilizumab in patients with rheumatoid arthritis is unaffected by comorbidity burden or obesity: Data from a US registry. J Rheumatol pii: jrheum.190282, 2020. PMID: 31941801 . DOI: 10.3899/jrheum.190282 
18 Plzák J, Bouček J, Bandúrová V, Kolář M, Hradilová M, Szabo P, Lacina L, Chovanec M and Smetana K Jr: The head and neck squamous cell carcinoma microenvironment as a potential target for cancer therapy. Cancers 11: 440, 2019. PMID: 30925774. DOI: $10.3390 /$ cancers 11040440

19 Tanaka T, Narazaki M and Kishimotoz T: Immunotherapeutic implications of IL-6 blockade for cytokine storm. Immunotherapy 8: 959-970, 2016. PMID: 27381687. DOI: 10.2217/imt-2016-0020

20 Xu X, Han M, Li T, Sun W, Wang D, Binqing Fu, Zhou Y, Zheng X, Yang Y, Li X, Zhang, X, Pan, A and Wei H: Effective treatment of severe COVID-19 patients with tocilizumab, 2020. Available at: https://www.ser.es/wp-content/uploads/2020/03/TCZ-and-COVID19.pdf [Last accessed on April 22, 2020].

21 Roche pleads for global harmony as it supercharges production of Actemra, COVID-19 tests. Available at: https:// www.fiercepharma.com/manufacturing/roche-pleads-for-globalharmony-as-it-supercharges-production-actemra-COVID-19-tests [Last accessed on April 22, 2020].

22 Genentech announces FDA approval of clinical trial for Actemra to treat hospitalized patients with severe COVID-19 pneumonia. Available at: https://www.gene.com/media/press-releases/14843/ 2020-03-23/genentech-announces-fda-approval-of-clin [Last accessed on March 23, 2020].

23 Wallace DJ, Linker-Israeli M, Metzger A and Stecher VJ: The relevance of antimalarial therapy with regard to thrombosis, hypercholesterolemia and cytokines in SLE. Lupus 2(Suppl 1): S13-S15, 1993. PMID: 8485565.

24 Kanvinde S, Singh Chhonker Y, Ahmad R, Yu F, Sleightholm R, Tang W, Jaramillo L, Chen Y, Sheinin Y, Li J, Murry DJ, Singh AB and Oupický D: Pharmacokinetics and efficacy of orally administered polymeric chloroquine as macromolecular drug in the treatment of inflammatory bowel disease. Acta Biomater 82: 158170, 2018. PMID: 30342282. DOI: 10.1016/j.actbio.2018.10.027

25 Zhou D, Dai SMD and Tong Q: COVID-19: a recommendation to examine the effect of hydroxychloroquine in preventing infection and progression. J Antimicrob Chemother dkaa114, 2020. PMID: 32196083. DOI: 10.1093/jac/dkaa114

26 Costedoat-Chalumeau N, Dunogué B, Morel N, Le Guern V and Guettrot-Imbert G: Hydroxychloroquine: a multifaceted treatment in lupus. Presse Med 43: e167-e180, 2014. PMID: 24855048. DOI: 10.1016/j.lpm.2014.03.007

27 Li H, Xiao H, Lin L, Jou D, Kumari V, Lin J and Li C: Drug design targeting protein-protein interactions (PPIs) using multiple ligand simultaneous docking (MLSD) and drug repositioning: discovery of raloxifene and bazedoxifene as novel inhibitors of IL-6/GP130 interface. J Med Chem 57: 632-641, 2014. PMID: 24456369. DOI: $10.1021 / \mathrm{jm} 401144 \mathrm{z}$

28 Ma H, Yan D, Wang Y, Shi W, Liu T, Zhao C, Huo S, Duan J, Tao J, Zhai M, Luo P, Guo J, Tian L, Mageta L, Jou D, Zhang C, Li C, Lin J, Lv J, Li S and Lin L: Bazedoxifene exhibits growth suppressive activity by targeting interleukin-6/glycoprotein 130/signal transducer and activator of transcription 3 signaling in hepatocellular carcinoma. Cancer Sci 110: 950-961, 2019. PMID: 30648776. DOI: $10.1111 /$ cas.13940
29 Andersson A, Bernardi AI, Stubelius A, Nurkkala-Karlsson M, Ohlsson C, Carlsten H and Islander U: Selective oestrogen receptor modulators lasofoxifene and bazedoxifene inhibit joint inflammation and osteoporosis in ovariectomised mice with collagen-induced arthritis. Rheumatology 55: 553-563, 2016. PMID: 26424839. DOI: 10.1093/rheumatology/kev355

30 Yadav A, Kumar B, Teknos TN and Kumar P: Bazedoxifene enhances the anti-tumor effects of cisplatin and radiation treatment by blocking IL-6 signaling in head and neck cancer. Oncotarget 8: 66912-66924, 2016. PMID: 28978005. DOI: 10.18632/oncotarget.11464

31 Burkhardt C, Bühler L, Tihy M, Morel $\mathrm{P}$ and Forni M: Bazedoxifene as a novel strategy for treatment of pancreatic and gastric adenocarcinoma. Oncotarget 10: 3198-3202, 2019. PMID: 31139333.

32 Thilakasiri P, Huynh J, Poh AR, Tan W, Nero TL, Tran K, Parslow AC, Afshar-Sterle S, Baloyan D, Hannan NJ, Buchert M, Scott AM, Griffin MD, Hollande F, Parker MW, Putoczki TL, Ernst $M$ and Chand AL: Repurposing the selective estrogen receptor modulator bazedoxifene to suppress gastrointestinal cancer growth. EMBO Mol Med 11: e9539, 2019. PMID: 30885958. DOI: 10.15252/emmm.201809539

33 Wei J, Ma L, Lai YH, Zhang R, Li H, Li C and Lin J: Bazedoxifene as a novel GP130 inhibitor for Colon Cancer therapy. J Exp Clin Cancer Res 38: 63, 2019. PMID: 30736824. DOI: $10.1186 / \mathrm{s} 13046-019-1072-8$

34 Jeon S, Ko M, Lee J, Choi I, Byun SY, Park S, Shum D and Kim S: Identification of antiviral drug candidates against SARS-CoV2 from FDA-approved drugs. BioRxiv, 2020. DOI: 10.1101/2020.03.20.9997301

35 Mo P, Xing Y, Xiao Y, Deng L, Zhao Q, Wang H, Xiong Y, Cheng Z, Gao S, Liang K, Luo M, Chen T, Song S, Ma Z, Chen $\mathrm{X}$, Zheng $\mathrm{R}$, Cao $\mathrm{Q}$, Wang $\mathrm{F}$ and Zhang $\mathrm{Y}$ : Clinical characteristics of refractory COVID-19 pneumonia in Wuhan. China Clin Infect Dis Mar pii: ciaa270, 2020. PMID: 32173725. DOI: $10.1093 / \mathrm{cid} / \mathrm{ciaa} 270$

36 Wenham C, Smithe J and Morgan R: COVID-19: the gendered impacts of the outbreak. LANCET 395: 846-848, 2020. PMID: 32151325. DOI: 10.1016/S0140-6736(20)30526-2
Received April 15, 2020

Revised April 16, 2020

Accepted April 23, 2020 